\title{
Estimating the thickness of hydrated ultrathin poly(o-phenylenediamine) film by atomic force microscopy
}

\author{
Ching-Chou Wu, Hsien-Chang Chang* \\ Institute of Biomedical Engineering, National Cheng Kung University, 1 Ta-Hseuh Road, Tainan 70101, Taiwan
}

Received 2 June 2003; received in revised form 13 October 2003; accepted 23 October 2003

\begin{abstract}
A novel method to measure ultrathin poly(o-phenylenediamine) (PPD) film electropolymerized on gold electrode in liquid was developed. It is based on the force versus distance curve (force curve) of atomic force microscopy (AFM). When $1-0.25 \mu \mathrm{m} / \mathrm{s}$ was chosen as the rising rate of the scanner, and $50 \%$ of the confidence interval $(\mathrm{CI})$ as the qualifying threshold value, the thickness of the hydrated polymer film could be calculated. This result was compared with one obtained from an AFM image. A step-like electrode fabricated by a photolithographic process was used. The height difference of the electrode before and after the PPD coating was imaged in liquid, and then the real thickness, $19.6 \pm 5.2 \mathrm{~nm}$, was obtained. The sample was also measured by estimating the transition range of the force curve of hydrated PPD film, and the thickness of the hydrated PPD film was determined to be $19.3 \pm 8.2 \mathrm{~nm}$. However, the results calculated by integrating the electropolymerized charge for the oxidation process of $o$-phenylenediamine (o-PD) was only one-third as large as it was when using the two previously described methods. This indicated that the structure of hydrated PPD film might have been swollen.
\end{abstract}

(c) 2003 Elsevier B.V. All rights reserved.

Keywords: Force curve; Hydrated; Thickness; Polymer; Atomic force microscopy

\section{Introduction}

In order to improve the selectivity of biosensors, a variety of polymer films were often used to modify the electrode surface as a selective layer to recognize specific molecules or as a functional matrix to immobilize an interesting probe, protein, or enzyme [1]. Electropolymerization of heteroaromatic compounds on an electrode surface has become one of the many effective methods used to modify electrodes for enzyme entrapment or to apply a stepwise coating as the outer barrier of a cross-linked enzyme layer. Organic conducting polymers like polyaniline, polypyrrole, polythiophene, and poly(o-phenylenediamine) (PPD) naturally have both a pore size and a charged group that prevent interfering compounds from permeating them, so they have drawn wide interest in biosensor fabrication in recent years. By using different electropolymerizing conditions, including monomer concentration, solvent conductivity, $\mathrm{pH}$ value, scanning-potential range, and applied scanning cycle, dif-

\footnotetext{
* Corresponding author. Tel.: +886-6-275-7575; fax: +886-6-276-0697.

E-mail address: hcchang@mail.ncku.edu.tw (H.-C. Chang).
}

ferent characteristics and functions of the conducting films can be obtained [2-9]. Differences in electropolymerized polymer film include thickness, surface roughness, $\mathrm{pH}$ response [4,5], electron-transfer kinetics [3,7], protection against metal corrosion [6], permselectivity for a dissolved species [2], and electrochromic properties [8]. Furthermore, the sensing efficiency of the sensor is related to the thickness of the electropolymerized polymer film. For example, the thickness of polypyrrole affects its potentiometric $\mathrm{pH}$ responses. Thinner film $(<2 \mu \mathrm{m})$ showed good linear responses to $\mathrm{pH}$ changes ranging between 2 and 12 [10]. The effects of the thickness of modified films on surface roughness or morphology [11-15], mass transport [16], charge transport [17], and measurement of polymer elasticity $[18,19]$ have been intensively discussed.

Currently, the development of a number of instruments and techniques to examine the magnitude of film thickness have been proposed, e.g. the infra-red spectrophotometer [20], the alpha-step profiler [21], the laser-ultrasound technique [22], the ellipsometry [23], the optical guided wave [16], the optical reflectance methodology [24], the electropolymerization charge $\left(24 \mathrm{mC} / \mathrm{cm}^{2}\right.$, ca. $0.1 \mu \mathrm{m}$ thick for polypyrrole) [25], etc. Most of these measurement methods, 
however, must be performed in vacuum or in air and be accompanied by a series of complicated samples, pretreatment, and numerical calculations. Therefore, measuring the real working thickness of hydrated polymer film in liquid is still a challenge.

Atomic force microscopy (AFM) provides the topography based on the feedback of force interaction between the apex of the AFM's cantilever tip and the target sample. AFM measurements can be made both in air and in liquid, its images are high resolution, and complex sample pretreatments are unnecessary. Because of these attributes and because it can easily be performed in liquid and directly measure height difference, AFM has been widely used to measure the morphology of biological samples [26,27] and polymers [28-32] as well as to estimate the elasticity of soft samples [33-35]. For instance, the nanometer level of thickness of highly oriented poly(tetrafluoroethylene) thin film varying from 7 to $32 \mathrm{~nm}$ can be easily determined by AFM topography in air [36]. In addition to measurement from an image, AFM has been used to investigate the elasticity of films of different thicknesses in liquid by means of the force versus distance curve (force curve) [18]. The Domke and Radmacher study [18] concluded that the measured elastic properties of thick gelatin film $(>300 \mathrm{~nm})$ seemed to be homogeneous and independent of the chosen range of analysis. For an extremely soft and very thin sample, e.g. thin gelatin film $(120 \mathrm{~nm})$, the cantilever tip can completely compress the sample and sense the underlying stiff substrate. Consequently, the force curve might be affected by the stiff substrate to produce a larger calculated Young's modulus, and the measured modulus depends on the chosen range of analysis. Simultaneously, they present an important concept for the calculation of the indentation of the cantilever tip by calculating the difference between the scanner displacement and cantilever deflection from force curve. Among the results of the Domke and Radmacher study, we noted a transitional slope area located in the middle region of the force curve for thin gelatin measurement. This area showed the penetration of the tip from the top of gelatin film to the hard underlying substrate.

In the present study, we focused on the force curve measurement and developed a novel method to estimate the extent of the transition area of the force curve of hydrated PPD film, and then to calculate the film thickness. To verify the result, a step-like gold/titanium (Au/Ti) electrode evaporated on flat glass was fabricated through the micro-photolithography process. The actual thickness of the ultrathin hydrated film was also measured based on height differences calculated from AFM images.

\section{Experimental}

\subsection{Electropolymerization of PPD film}

$o$-Phenylenediamine (o-PD) was purchased from Riedelde Haën (Germany); all other chemicals for fabrication of the step-like electrodes were from J.T. Baker (USA). The electropolymerization of PPD film on an Au electrode in phosphate buffer solution (PBS, pH 7.4) containing $5 \mathrm{mM}$ of $o$-PD was carried out with a BAS 100B Electrochemical Workstation (Bioanalytical Systems Inc., West Lafayette, IN). Cyclic voltammetry (CV) was performed in an electrochemical cell constructed by the deposited Au electrode, Pt wire, and $\mathrm{Ag} / \mathrm{AgCl} / 3 \mathrm{M} \mathrm{NaCl}$ electrode as the working, counter, and reference electrodes, respectively. The cyclic scanning condition was set at $50 \mathrm{mV} / \mathrm{s}$ from 0 to $900 \mathrm{mV}$ and then back to $0 \mathrm{mV}$.

\subsection{Fabrication of step-like Au electrode}

A step-like Au electrode as the working electrode was fabricated using the photolithographic techniques of lift-off and wet chemical etching [37]. A glass slide used as a substrate was immersed first in acetone and then isopropanol for cleaning before $\mathrm{Au}$ deposition. The working electrode consisted of a $45 \mathrm{~nm}$-thick Au layer deposited on a seed layer of $35 \mathrm{~nm}$-thick Ti $3.96 \mathrm{~mm}^{2}$ in area with a leading pad $(200 \mu \mathrm{m} \times 15 \mathrm{~mm})$.

\subsection{Thickness estimation from AFM image}

A contact model AFM (CP; Park Scientific Instruments (PSI), Sunnyvale, CA) was used to image the height difference of the Au electrode before and after electropolymerization of PPD in $10 \mathrm{mM}$ PBS. We used a silicon nitride cantilever (Microlever 06A; PSI) with $0.05 \mathrm{~N} / \mathrm{m}$ of force constant with an integrated tip $3 \mu \mathrm{m}$ in height, a $35^{\circ}$ halfcone angle, and a curvature radius of $50 \mathrm{~nm}$. Low-contact force was chosen to reduce deformation of the PPD surfaces. We used a force less than $1.5 \mathrm{nN}$ and a $0.3-1 \mathrm{~Hz}$ scanning rate in the $x y$-plane followed by a different observation range. Before image acquisition, the AFM system scanner was calibrated in the $z$-axis by a standard specimen (model TGZ01: NT-MDT Co., Moscow, Russia) $26 \mathrm{~nm}$ in height. When the desired height of the electrode was compared with that of the image, it was placed as completely as possible in the same area to eliminate the effect of substrate flatness. In order to reduce the non-linear properties of the scanner, a suitably sized image was chosen. Furthermore, in order to determine the edge effect of the step-like electrode, a program was designed using LabVIEW software (National Instruments (NI) Co., Austin, TX) to estimate four separate areas located from the electrode edge inward $1 \mu \mathrm{m}$ (region i), $1-2 \mu \mathrm{m}$ (region ii) $2-3 \mu \mathrm{m}$ (region iii), and 3-4 $\mu \mathrm{m}$ (region iv).

\subsection{Data analysis of force curve}

The slope of a force curve is related to the elastic properties of the sample. The force curve test on a hard Au substrate is shown in Fig. 1a. The non-contact (NC) area indicates that there was no contact between the cantilever tip and the stiff substrate when the underlying scanner rose. The deflection 

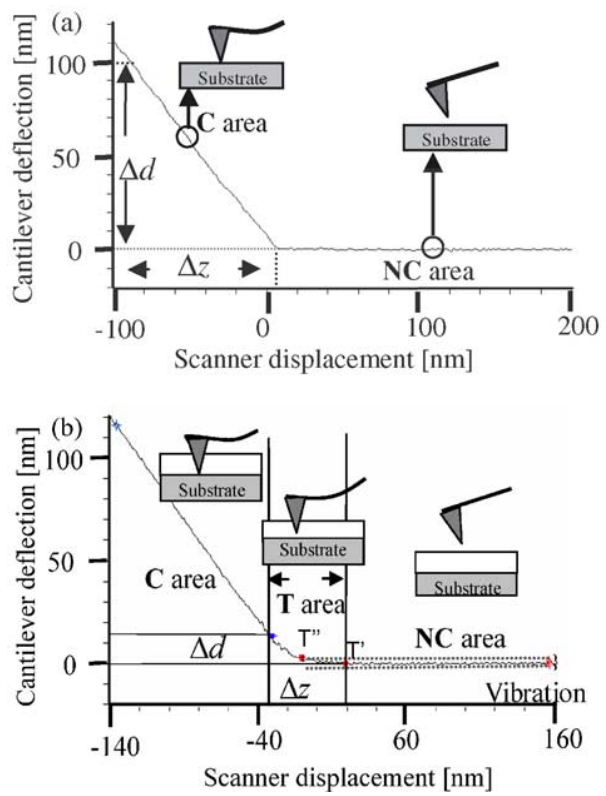

Fig. 1. The force curve measured on different types of samples during the extension of the scanner: (a) on hard Au substrate; (b) on hydrated PPD film in $10 \mathrm{mM}$ PBS ( $\mathrm{pH} 7.4$ ).

of the cantilever $(\Delta d)$ was identical to the scanner displacement $(\Delta z)$ in $z$ direction: $\Delta d=\Delta z$, as shown in the contact (C) interval of Fig. 1a. According to the previous study [18], the hydrated ultrathin PPD film was soft and thin enough. If a cantilever force constant smaller than the substrate and larger than the film was chosen, the tip could completely penetrate the thin film and touch the hard substrate [18]. Its force curve is shown in Fig. 1b. The transition (T) area displays the penetration of the tip through the hydrated PPD film. This indentation of the tip would result in a smaller deflection of the cantilever, and then the thickness of the hydrated film $(\delta)$ would equal the value of $\Delta z-\Delta d$. Using LabVIEW (NI) software, we designed and developed a computer program to analyze the force curve by distinguishing the extent of the transition area from the force curve. For the program to work, it is essential to determine the starting and ending point of the transition area. At the beginning of the force curve, there is no contact between the cantilever tip and polymer film, thus the deflection of the cantilever is zero. When the film is successively raised by the scanner, the starting point of the transient area is located at the first turning point of the force curve. During the actual measurement, however, the first point at which the cantilever tip touches the film is difficult to identify. The cantilever will be affected by tiny vibration caused by surrounding unstable liquid; the instability is the result of a thermal effect and the consequent movement of the scanner. To solve this problem, we applied a statistical method to represent the vibration distribution of the cantilever by using the confidence interval to describing the possible values of a sample distribution. For example, if the $\mathrm{T}^{\prime}$ point of Fig. 1b locates at the mean value of the cantilever vibration, its $\mathrm{CI}$ value is approximately $0 \%$. On the other hand, if the $\mathrm{T}^{\prime \prime}$ locates at the point fully over the cantilever vibration, its assigned CI value is $100 \%$. The beginning position of the transient area was assigned a value larger than four different qualifying thresholds at 25, 50, 75, and $95 \% \mathrm{CI}$ of the NC area. Because the cantilever deflection in the NC area was regarded as a normal distribution, its vibration distribution range can be represented by different CI values. If the cantilever touches the film, it means that an additive force allows the deflection of the cantilever to move away from the original vibration, and then the starting point of the transition area can be identified. Furthermore, as the film keeps rising, the cantilever tip will penetrate it. When the cantilever tip touches the substrate, the magnitude of the cantilever deflection will equal the rising distance of the hard substrate. Therefore, the slope in the $\mathrm{C}$ area can be set at -1 (Fig. 1b). The end point of the $\mathrm{T}$ area is located at the intersection of the fitting function and the original force curve. We compared the results obtained using different qualifying threshold values with the AFM height image to determine the most suitable CI threshold. In addition, different rising rates of the scanner ranging from 5 to $0.025 \mu \mathrm{m} / \mathrm{s}$ were used to find the optimum measuring condition.

\section{Results and discussion}

\subsection{Fabrication of PPD membrane}

The CV behavior of electropolymerization in PBS containing $5 \mathrm{mM}$ of $o$-PD achieved on the Au electrode is depicted by a large irreversible oxidation peak on the first scan, and then by significantly reduced and falling oxidation current in successive scans (Fig. 2a). This result was attributed to the film being also resistive, thus hindering further monomer oxidation and polymer deposition [4]. The cumulative deposited charge, and its conversion into percentage, from 15 cycles of CV scanning between 0 and $+0.9 \mathrm{~V}$ are shown in Fig. 2b. It can be seen that a plateau value is almost reached after 5 cycles, and that $96.5 \%$ of the charge has passed through after the 7 th cycle. The greater part of the electro-oxidation to form PPD occurred during the prior $\mathrm{CV}$ scanning. Actually, the monomer $o-\mathrm{PD}$, an aniline derivative, can be electropolymerized in acidic solution so that it can be developed into a thicker conductive membrane. We fabricated the PPD membrane in neutral solution through 7 cycles of $\mathrm{CV}$ as a sample for our new method of measuring an ultrathin hydrated-membrane for its potential application as biomaterial.

Because the PPD film was derived from an oxidized monomer, its thickness could be theoretically estimated from the corresponding charge in its electro-oxidation. Before we did this, we determined the actual surface area by following the method of Michri and Pshchenichnikov [38]; we calculated it using the charge amount of chemisorbed oxygen on a gold electrode in $0.5 \mathrm{M}$ of $\mathrm{H}_{2} \mathrm{SO}_{4}$. As a result, we determined the actual area of the resulting gold surface 

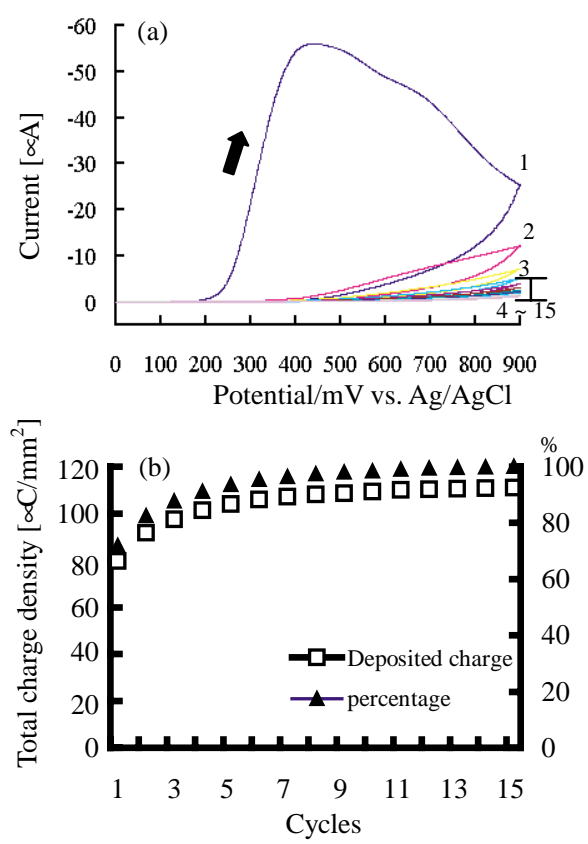

Fig. 2. (a) Repetitive cyclic voltammogram for the oxidation of $5 \mathrm{mM}$ $o$-PD at $3.96 \mathrm{~mm}^{2}$ Au electrode with an interval of 2 min each cycle in phosphate buffer solution; scan rate: $50 \mathrm{mV} / \mathrm{s}$. (b) Total charge density and accumulative percentage vs. number of cycles.

to be 1.9 times as large as its geometric area. We also calculated the charge density via 7-cycle electropolymerization to be $11.6 \mathrm{mC} / \mathrm{cm}^{2}$. Alternatively, using molecular modeling of $o$-PD monomer, one could determine its cross-sectional dimension of ca. $3 \AA \times 5 \AA$ and its depth of $1.4 \AA$, and the film thickness may be calculated by the number of monomer units deposited by a two-electron transfer during the oxidation of $o$-PD [39]. Consequently, PPD films polymerized via 7 cycles by $\mathrm{CV}$ scanning and with a thickness of ca. $7.6 \pm 1.2 \mathrm{~nm}(n=6)$ were obtained.

\subsection{Height difference from AFM image}

The topographical image of the bare Au electrode fabricated by the wet etching process depicts a sharp step-like edge (Fig. 3a). This topography makes it relatively simple to measure the edge of the electrode, which helps us to compare the height difference before and after electropolymerization. The fabrication based on the lift-off process shows a slowly rising slope at the edge of the electrode (Fig. 3b). The slope can be attributed to the interference of photoresist of the castle-like model with the gold particles deposited by evaporation during the fabrication of the Au electrode [37].

The scanner is made of piezoelectric material. This means that the scanner movement not only has a non-linear relationship corresponding to the applied voltage, which lets the derivation between actual and ideal displacement increase with larger scanning size, but also that it has a cross-coupling effect resulting in a spurious $z$-axis displacement when performing a scan in the $x$ - or $y$-axis direction. Consequently, a piezoelectric tube scans not in a plane, but in an arc. When
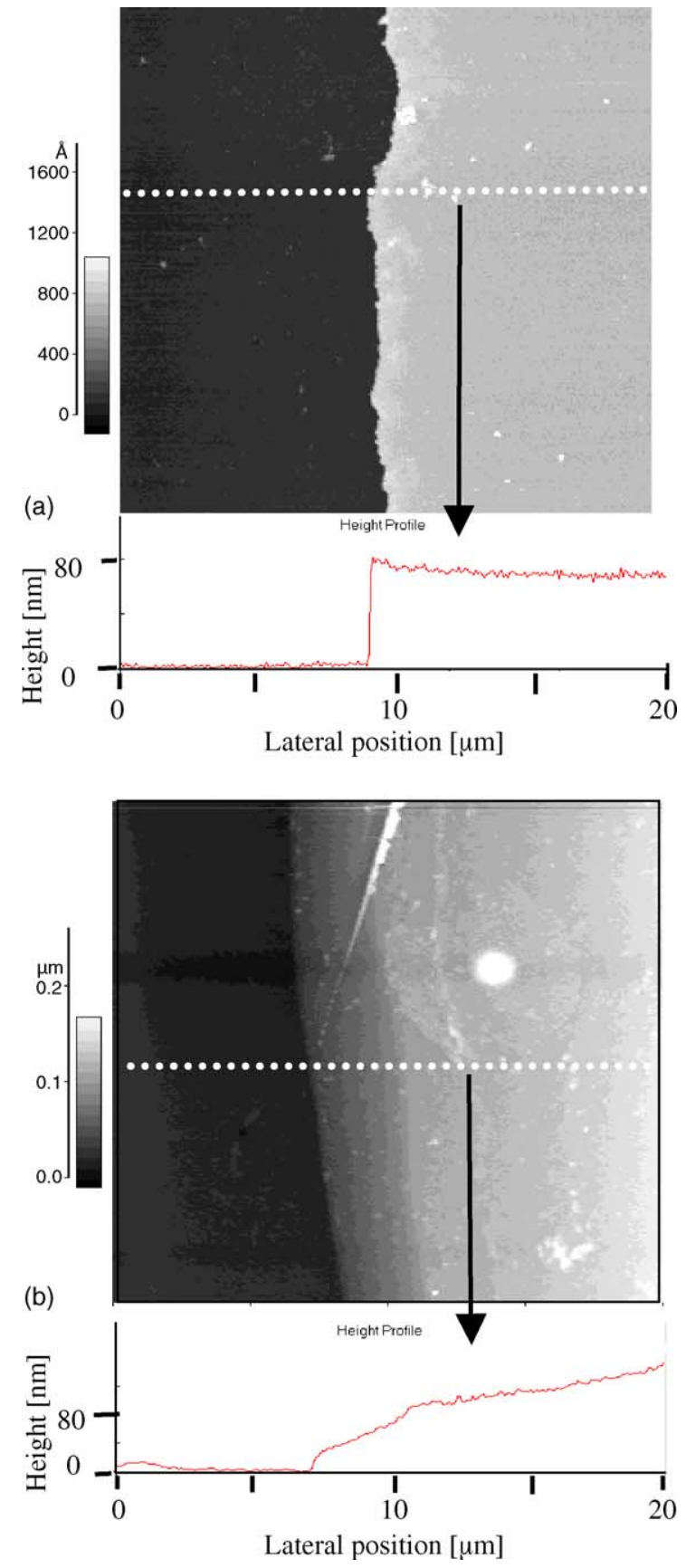

Fig. 3. Comparison of shape of bare electrodes from different photolithography process: (a) wet chemical etching process; (b) lift-off process. Upper image is the electrode topography. Lower image is the profile of the dash line.

we actually measured it, the arc appeared as a significant curvature of more than $20 \mu \mathrm{m}$ with the largest height difference about $20 \mathrm{~nm}$ across the electrode plane (Fig. 4a). If the scan size was controlled within $10 \mu \mathrm{m}$, however, the largest height difference was only $5 \mathrm{~nm}$ (Fig. 4b). This so-called cross-coupling effect tends to decrease with smaller scanning size. We therefore chose to evaluate the height of $\mathrm{Au}$ deposited on the electrode in the $10 \mu \mathrm{m}$ mode.

A comparison of the AFM topography of the Au electrode 


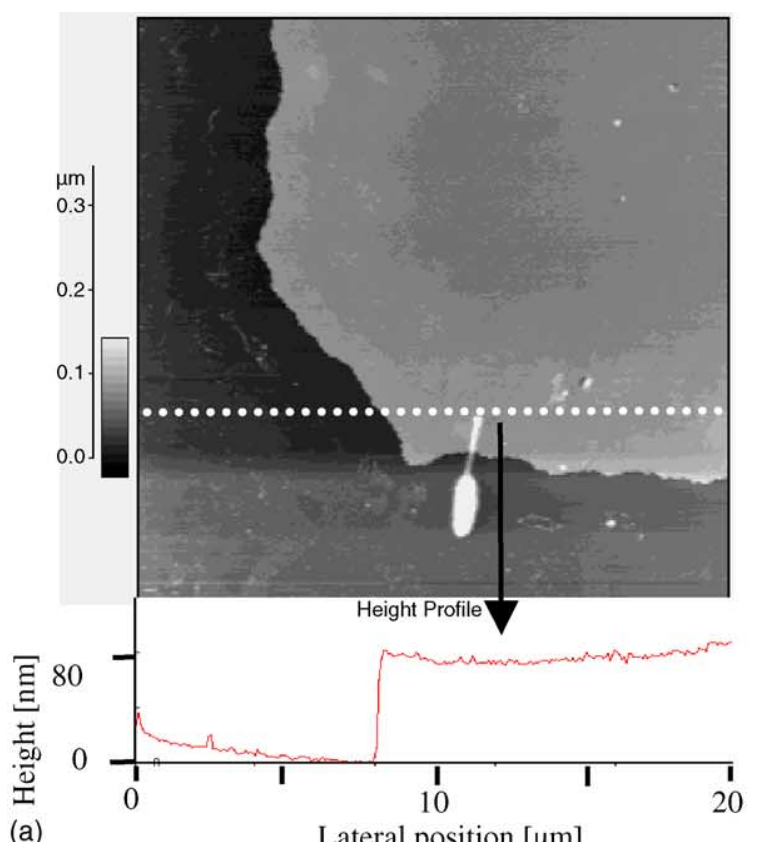

(a)

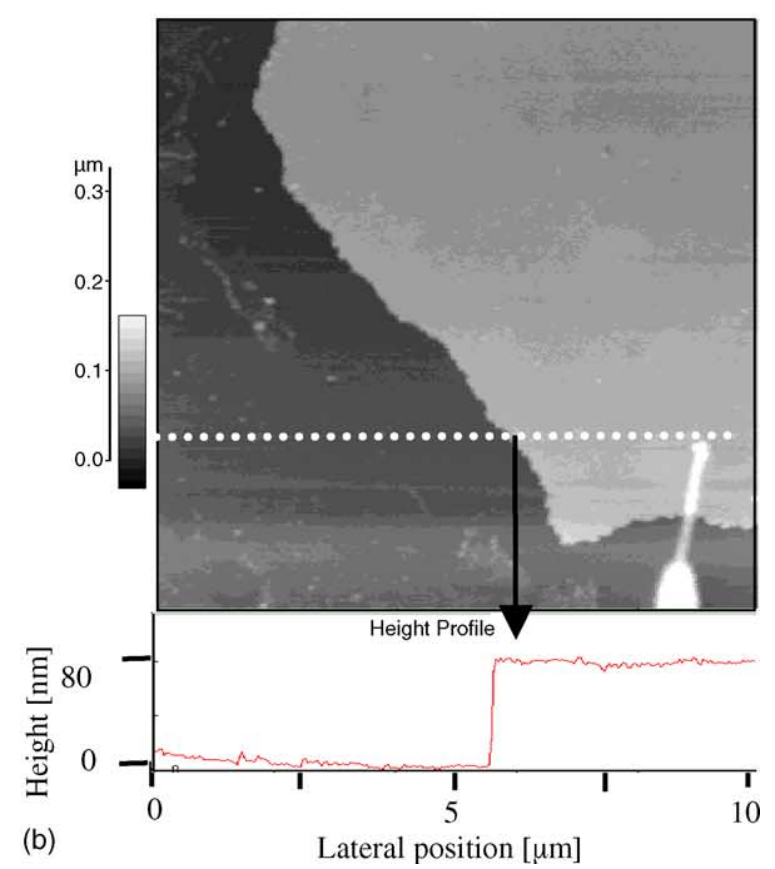

Fig. 4. Effect of non-linear properties of scanner on different scanning size: (a) $20 \mu \mathrm{m}$; (b) $10 \mu \mathrm{m}$. Upper image is the electrode topography. Lower image is the profile of the dash line.

in liquid before and after the PPD was modified as shown in Fig. 5. We found that the region ranging from the electrode edge inward $1.8 \mu \mathrm{m}$ included a deposited layer with larger particles along the electrode edge (Fig. $5 \mathrm{c}$ and d). This suggested that a higher current density accompanied by a more sufficient diffusion occurred at the electrode edge at the same time as the oxidation of $o$-PD. This is called the edge effect. To compare the change in the surface roughness of the deposits on the Au electrode, after electropolymeriza- tion we measured the area with a $4 \mu \mathrm{m}$ scan. A location not at the electrode edge was chosen to avoid the interference of the edge effect. The root mean square roughness of the bare electrode and the electrode after PPD modification was 1.8 and $3.1 \mathrm{~nm}$, respectively. When we zoomed in to $1 \mu \mathrm{m}$ on the same scanning area, the gold nodules were clearly visible, and the mean sizes of nodules of raw gold and nodules after PPD coating were approximately 60 and $85 \mathrm{~nm}$, respectively (Fig. 6). The greater surface roughness can be attributed to the larger size of the nodules.

The statistical evaluation of electrode height and surface roughness before and after PPD coating is shown in Fig. 7. Mean deposited film thickness close to the electrode edge (first two regions in Fig. 7) was slightly thicker than in the region farthest from the edge (fourth region in Fig. 7). The surface roughness data strongly showed that the closer to the electrode edge, the greater the roughness. PPD thickness was calculated by integrating the oxidation charge of $o$-PD from 0 to $+0.9 \mathrm{~V}$, and by applying the AFM image described above. The thickness obtained from the AFM image was about three times that estimated from the oxidation charge. This result may be attributed to either the hydrated PPD film becoming swollen [7], or to the polymerization of $o$-PD requiring spatial coordination, not compact polymerization one by one. Therefore, we offered the real thickness obtained from the AFM image as the standard value for the calculation of force curve.

\subsection{Film thickness from force curve}

The force curve presented here was an alternative method for measuring the PPD thickness. Fig. 1 shows the virtually measured force curves for the stiff Au electrode and the soft hydrated PPD film. To compare the measuring force curve of the Au electrode, the force curve of the hydrated PPD film was obviously observed a transitional area. The silicon nitride tip was chemically inert and measured the film in $10 \mathrm{mM}$ PBS (pH 7.4), which decreases the protonization of PPD [4] and diminishes the double-layer effect [40]. As a result, the surface of the tip showed a slight negative charge and the PPD film had a slight positive charge in PBS. There is no obvious repulsive force between the tip and the PPD film, and the electrolyte concentration of $10 \mathrm{mM}$ should prevent the effect of hydration force induced by over hundreds of millimolars of electrolyte [40]. Therefore, the effects of the chemical factors on force curve measurement were not discussed.

To avoid the interference of the edge effect, we chose 30 points located $4 \mu \mathrm{m}$ from the edge. We tested using seven different rising rates of the scanner $(0.025,0.1,0.25,0.5$, 1,2 , and $5 \mathrm{~Hz}$ ) and four different deviations of threshold for the measured force curve $(25,50,75$, and $95 \% \mathrm{CI})$. For each rising rate of the scanner, the force curves were performed 30 times at different positions on the PPD film, and the thickness was calculated (Table 1). After qualification by different $\mathrm{CI}$ criteria, we found that the $50 \% \mathrm{CI}$ threshold 

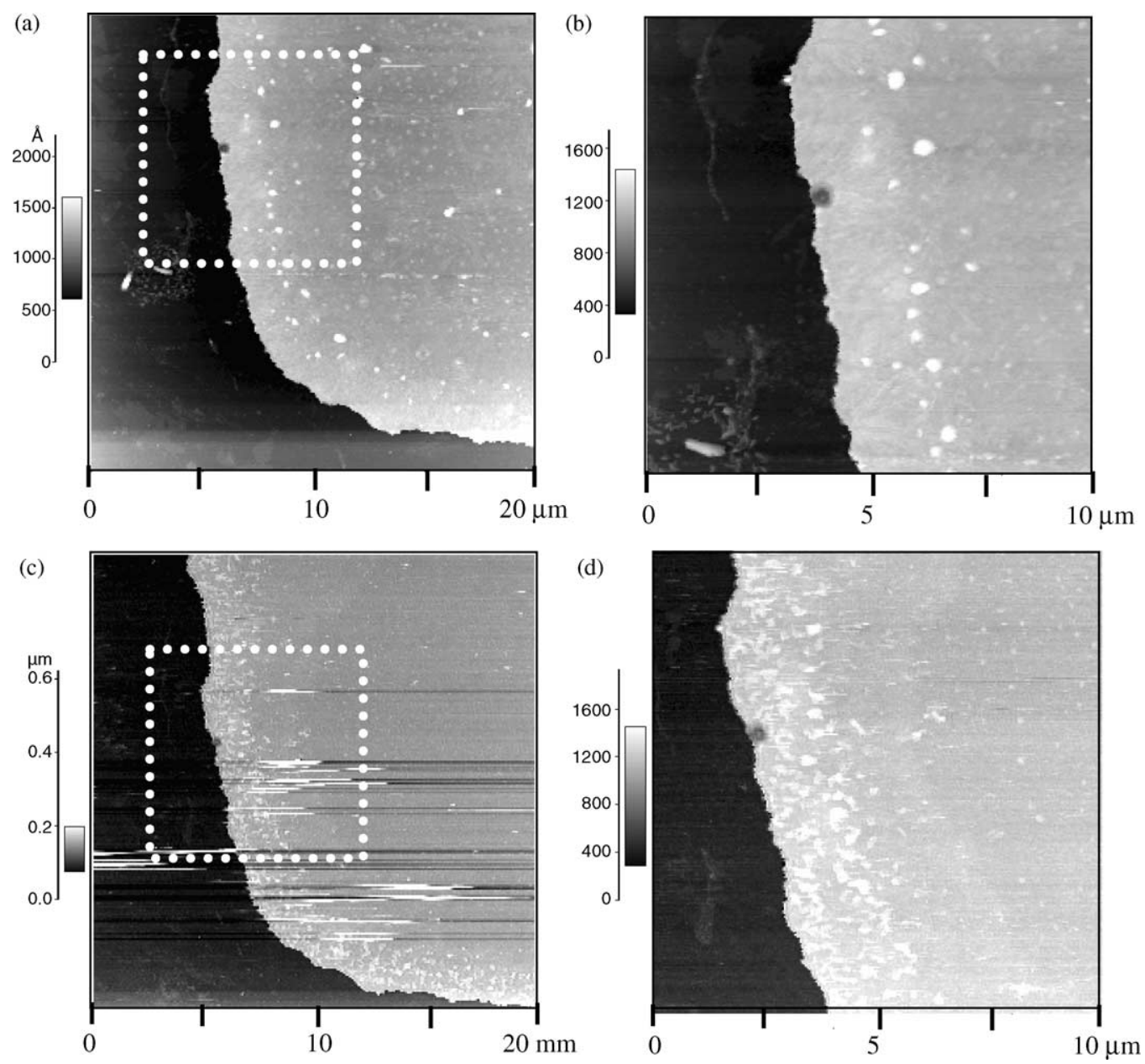

Fig. 5. Comparison of electrode topography of the same area before and after PPD electropolymerization: (a) bare electrode in liquid at $20 \mu \mathrm{m}$; (c) after PPD film modification in liquid at $20 \mu \mathrm{m}$; (b) and (d) zoom in to $10 \mu \mathrm{m}$ on (a) and (c), respectively.

provided a value closest to the one obtained by image measurement. The measurement provided at $25 \%$ CI was too thick, because it could not fully represent the main part of the free vibration range in the $\mathrm{NC}$ area. By using more than the $50 \%$ CI sampling, the extra cantilever deflection caused by the hydrated film was included to NC area, so the measurements were too thin, especially for $95 \%$ CI.

Different rising rates of the scanner were used to determine optimum measuring conditions. With $50 \% \mathrm{CI}$ as the qualifying threshold, only the three successive measurements at the rising rates of $1,0.5$, and $0.25 \mu \mathrm{m} / \mathrm{s}$ were relatively close to the ca. $19.3 \mathrm{~nm}$ figure based on the AFM image. In general macroscopic view, using different loading rates of force, the bulk polymer material shows a brittle behavior at a fast loading rate of force and a creeping behavior at a slow rate [41]. If the rising rate were set to be excessively fast, such as at $2 \mu \mathrm{m} / \mathrm{s}$, the thickness measurement would be smaller (ca. $17.8 \pm 7.1 \mathrm{~nm}$, at $50 \% \mathrm{CI}$ ). When the rising rate was increased to $5 \mu \mathrm{m} / \mathrm{s}$ in our experiment, the transient area of the force curve would disappear. This can be attributed to one of the two causes: (1) a violent turbulence caused primarily by the viscosity drag of the solution to lead to an unstable acquisition condition [40]; or

Table 1

Thickness of hydrated PPD film calculated by different qualifying threshold $(25,50,75$, and $95 \%$ CI) vs. different rising rate of scanner

\begin{tabular}{|c|c|c|c|c|c|c|}
\hline \multirow{2}{*}{$\begin{array}{l}\text { Confidence } \\
\text { interval(\%) }\end{array}$} & \multicolumn{6}{|c|}{ Thickness of hydrated PPD film $(\mathrm{nm})(n=30)$, rate $(\mu \mathrm{m} / \mathrm{s})$} \\
\hline & 2 & 1 & 0.5 & 0.25 & 0.1 & 0.025 \\
\hline 25 & $20.4 \pm 9.1$ & $22.9 \pm 10.9$ & $22.4 \pm 11.9$ & $25.2 \pm 13.5$ & $25.2 \pm 13.9$ & $31.1 \pm 7.7$ \\
\hline 50 & $17.8 \pm 7.1$ & $18.8 \pm 7.1$ & $19.3 \pm 8.2$ & $19.6 \pm 8.2$ & $21.7 \pm 8.6$ & $28.3 \pm 8.7$ \\
\hline 75 & $16.4 \pm 7.2$ & $15.9 \pm 6.3$ & $18.1 \pm 9.0$ & $18.1 \pm 8.2$ & $19.8 \pm 8.7$ & $26.0 \pm 7.5$ \\
\hline 95 & $14.2 \pm 7.2$ & $13.6 \pm 6.2$ & $15.1 \pm 6.2$ & $16.8 \pm 7.6$ & $14.5 \pm 4.3$ & $20.5 \pm 7.3$ \\
\hline
\end{tabular}



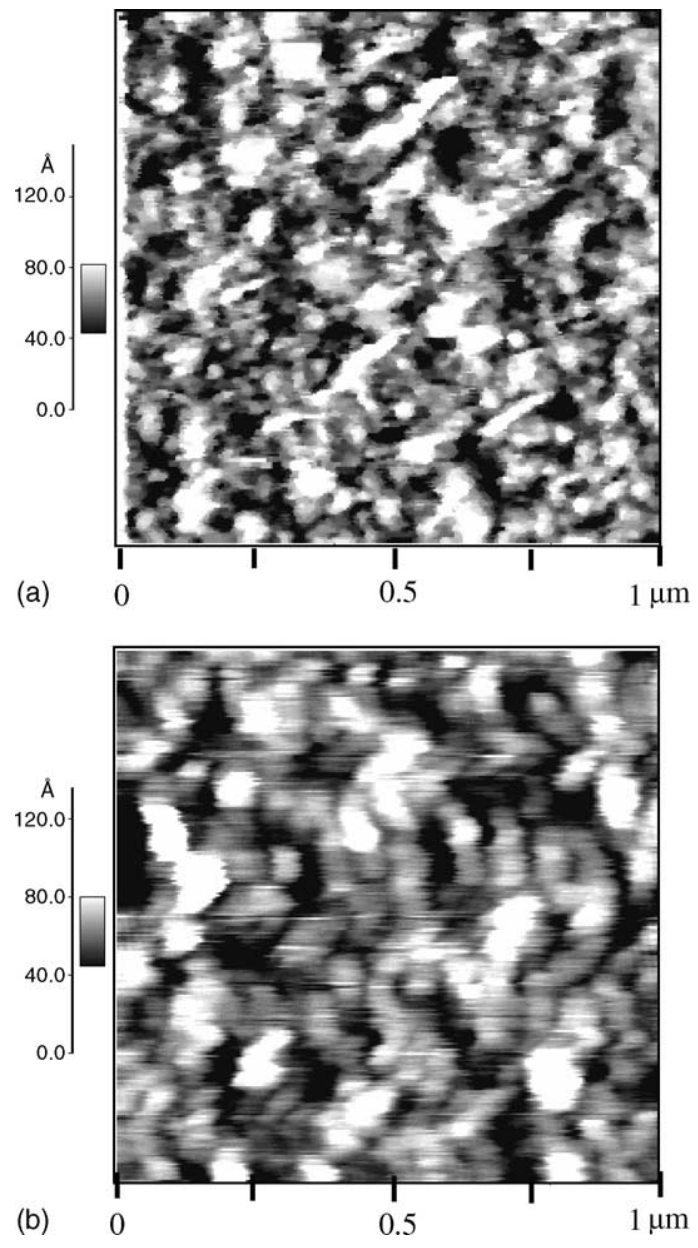

Fig. 6. Comparison of AFM image of electrode surface: (a) bare electrode; (b) after PPD film modification. Brighter spots are the nodules.

(2) the effect of brittle behavior of the polymer film on the measurement of force curve at a fast loading rate of force. On the other hand, the thickness measurement was larger at the lower rising rates, particularly at $0.025 \mu \mathrm{m} / \mathrm{s}$. This result

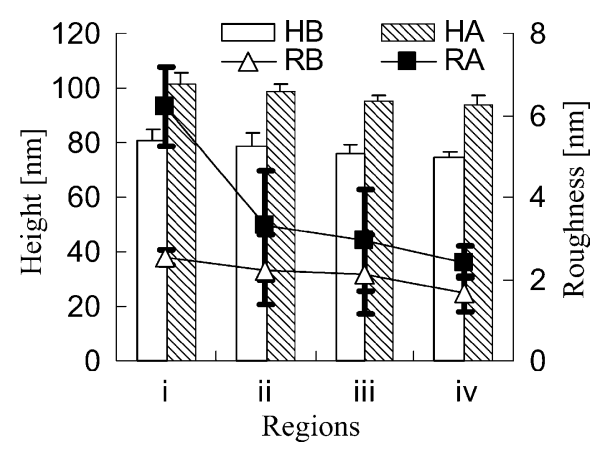

Fig. 7. Statistical chart of electrode height and surface roughness at four different regions: (i) from edge inward to $1 \mu \mathrm{m}$ (film thickness, $21.8 \pm 6.3 \mathrm{~nm}$ ); (ii) from 1 to $2 \mu \mathrm{m}$ (film thickness, $21.5 \pm 3.7 \mathrm{~nm}$ ); (iii) from 2 to $3 \mu \mathrm{m}$ (film thickness, $20.1 \pm 5.0 \mathrm{~nm}$ ); and (iv) from 3 to $4 \mu \mathrm{m}$ (film thickness, $19.6 \pm 5.2 \mathrm{~nm}$ ). HB: electrode height before coating; HA: electrode height after coating; RB: surface roughness before coating; RA: surface roughness after coating. suggested that the cantilever was more sensitive to the interactive force between the tip and the surface of PPD film and that the creep behavior of polymer film resulted in a longer force-buffer area. We determined, therefore, that rising rates of $1,0.5$, and $0.25 \mu \mathrm{m} / \mathrm{s}$ are most suitable for the measurement of the resulting PPD film. In addition to the effect of the loading rate of force, the radius of the tip could affect the results of the force curve. The sharper tip with a $10 \mathrm{~nm}$ radius and the same force constant $(0.046 \mathrm{~N} / \mathrm{m}$, Nanosensor, Germany) was used once to measure the same hydrated film. But the transitional area could not be apparently obtained. This result suggested that, at the same force loading, the larger contact area of the tip was more sensitive than the smaller to the interactive force between the tip and the film. The tip with larger radius was more suitable for measuring ultrathin film.

In this study, the first contact point between the cantilever tip and PPD film was figured out by using the statistic method from force curve. In Domke and Radmacher study [18], they chose a point being a value of cantilever deflection larger than $10 \mathrm{~nm}$ for the first point of analytical range. The contact point $Z_{0}$ and $d_{0}$ is not used as the first point of the analytical range owing to its absolute value being unknown. As a result, the thinner the gelatin thickness is, the closer the analysis range is to the hard substrate. It results in measuring a larger than actual value elasticity of the sample. However, the contact point can be determined in our experiment, a more virtual value of the elasticity of ultrathin film may be measured, one that does not reflect the effect of the substrate.

\section{Conclusions}

This is the first time that AFM has been used to evaluate the thickness of electropolymerized PPD film in liquid by analyzing the relationship of force curves. The result demonstrated good agreement with the value obtained by estimating the height difference of the AFM image before and after electropolymerization. We also found that using rising rates of $1-0.25 \mu \mathrm{m} / \mathrm{s}$ and a $50 \% \mathrm{CI}$ as the qualifying threshold constituted the most suitable conditions for determining the thickness of the hydrated polymer film. The AFM image technique result that the thickness of hydrated PPD film was approximately three-fold that was determined by calculating the deposited charge indicates that integrating the electropolymerized charge will not lead to the real thickness because of the swelling of the hydrated PPD film. Furthermore, the technique of analyzing AFM force curve behavior in liquid provides a reliable method for obtaining the true thickness of polymer film too thin to be measured by optical microscope. However, the edge effect during the process in electropolymerization should not be neglected. This method can also be applied to measuring in liquid the thickness of other PPD films using different electropolymerizing conditions. 


\section{Acknowledgements}

We thank the National Science Council (grant no. NSC892218-E-006-069 and grant no. NSC 90-2218-1-006-037) of the Republic China for financial support.

\section{References}

[1] J.S. Schultz, in: R.F. Taylor (Ed.), Handbook of Chemical and Biological Sensors, Institute of Physics Publishing, London, 1996, p. 3.

[2] Y. Ohnuki, H. Matsuda, T. Ohsaka, N. Oyama, J. Electroanal. Chem. 158 (1983) 55.

[3] K. Chiba, T. Ohsaka, N. Oyama, J. Electroanal. Chem. 217 (1987) 239.

[4] W.R. Heineman, H.J. Wieck, A.M. Yacynych, Anal. Chem. 52 (1980) 345.

[5] G. Cheek, C.P. Wales, R.J. Nowak, Anal. Chem. 55 (1983) 380

[6] A. Volkov, G. Tourillon, P.C. Lacaze, J.E. Dubois, J. Electroanal. Chem. 116 (1980) 279.

[7] K. Martinusz, E. Czirok, G. Inzelt, J. Electroanal. Chem. 379 (1994) 437.

[8] K. Chiba, T. Ohsaka, Y. Ohnuki, N. Oyama, J. Electroanal. Chem. 219 (1987) 117

[9] L. Sabbatini, C. Malitesta, E.D. Giglio, I. Losito, L. Torsi, P.G. Zambonin, J. Electron. Spectrosc. 100 (1999) 35.

[10] K.K. Shiu, F.Y. Song, K.W. Lau, J. Electroanal. Chem. 476 (1999) 109.

[11] K.C. Khulbe, T. Matsuura, S.H. Noh, J. Membr. Sci. 145 (1998) 243.

[12] J.K. Avlyanov, J.Y. Josefowicz, A.G. MacDiarmid, Synth. Met. 73 (1995) 205.

[13] T. Silk, Q. Hong, J. Tamm, R.G. Compton, Synth. Met. 93 (1998) 59.

[14] X. Cui, J.F. Hetke, J.A. Wiler, D.J. Anderson, D.C. Martin, Sens. Actuators A-Phys. 93 (2001) 8.

[15] W.L. Yuan, E.A. O’Rear, G. Cho, G.P. Funkhouser, D.T. Glatzhofer, Thin Solid Films 385 (2001) 96.

[16] N.F. Fell Jr., P.W. Bohn, Anal. Chem. 65 (1993) 3382.
[17] V.V. Kondratiev, A.V. Tikhomirova, V.V. Malev, Electrochim. Acta 45 (1999) 751.

[18] J. Domke, M. Radmacher, Langmuir 14 (1998) 3320.

[19] S.A. Chizhik, Z. Huang, V.V. Gorbunov, N.K. Myshkin, V.V. Tsukruk, Langmuir 14 (1998) 2606.

[20] S. Kawata, K. Takeuchi, J. Opt. Soc. Am. A 8 (1991) 1055.

[21] L.L. Spangler, J.M. Torkelson, J.S. Royal, Polym. Eng. Sci. 30 (1990) 644.

[22] R.J. Dewhurst, L. Noui, Q. Shan, Rev. Sci. Instrum. 61 (1990) 1736.

[23] S. Villette, M.P. Valignat, A.M. Cazabat, F.A. Schabert, A. Kalachev, Phys. A 236 (1997) 123.

[24] K. Hirvi, M.J. Pekola, M. Paalanen, Rev. Sci. Instrum. 65 (1994) 2735.

[25] A.F. Diaz, J.I. Castillo, J. Chem. Soc. Chem. Commun. (1980) 397.

[26] V. Parpura, P.G. Haydon, E. Henderson, J. Cell Sci. 104 (1993) 427.

[27] R. Lal, B. Drake, D. Blumberg, D.R. Saner, P.K. Hansma, S.C. Feinstein, Am. J. Physiol. 269 (1995) C275.

[28] H. Seyama, K. Maki, J. Vac. Sci. Technol. B. 15 (1997) 192.

[29] R. Nyffenegger, E. Ammann, H. Siegenthaler, R. Kötz, O. Haas, Electrochim. Acta 40 (1995) 1411.

[30] T. Gesang, R. Höper, S. Dieckhoff, V. Schlett, W. Possart, O.D. Hennemann, Thin Solid Films 264 (1995) 194.

[31] Y. Kobiki, A. Suzuki, Int. J. Adhes. Adhes. 19 (1999) 411.

[32] J.N. Barisci, R. Stella, G.M. Spinks, G.G. Wallace, Electrochim. Acta 46 (2000) 519.

[33] H.Y. Nie, M. Motomatsu, W. Mizutani, H. Tokumoto, Thin Solid Films 273 (1996) 143.

[34] A. Vinckier, G. Semenza, FEBS Lett. 430 (1998) 12.

[35] C.T. Gibson, G.S. Watson, L.D. Mapledoram, H. Kondo, S. Myhra, Appl. Surf. Sci. 144-145 (1999) 618.

[36] P. Dietz, P.K. Hansma, K.J. Ihn, F. Motamedi, P.J. Smith, Mater Sci. 28 (1993) 1372.

[37] M. Madou, in: M. Madou (Ed.), Fundamentals of Microfabrication, CRC Press, New York, 1997, p. 14.

[38] A.A. Michri, A.G. Pshchenichnikov, Soviet Electrochem. 8 (1972) 351-352.

[39] S. Myler, S. Eaton, S.P.J. Higson, Anal. Chim. Acta. 357 (1997) 55.

[40] B. Cappella, G. Dietler, Surf. Sci. Rep. 34 (1999) 1.

[41] W.D. Callister, Jr., Materials Science and Engineering: An Introduction, Wiley, New York, 1994, p. 473. 